\title{
Bahaya Kosmetika Pemutih yang Mengandung Merkuri dan Hidroquinon serta Pelatihan Pengecekan Registrasi Kosmetika di Rumah Sakit Gunung Jati Cirebon
}

\author{
The Danger of Using Whitening Cream which Contains Mercury and \\ Hydroquinone and Training in Cosmetic Registration checks at Gunung Jati \\ Hospital Cirebon
}

\author{
Sulistiorini Indriaty ${ }^{1}$, Nur Rahmi Hidayati ${ }^{2}$, Arsyad Bachtiar ${ }^{3}$ \\ D3 Farmasi, Sekolah Tinggi Farmasi Muhammadiyah Cirebon, Cirebon \\ ${ }^{1}$ lovely kalila@yahoo.co.id, ${ }^{2}$ salsabilla_83@yahoo.com
}

Riwayat Artikel: Dikirim 29 September 2018; Diterima 28 November 2018; Diterbitkan 30 November 2018

\begin{abstract}
Abstrak
Produk pemutih kulit adalah salah satu produk kosmetik yang mengandung bahan aktif yang dapat menekan atau menghambat pembentukan melanin atau menghilangkan melanin yang sudah terbentuk sehingga memberikan warna kulit yang lebih putih. Keterbatasan pengetahuan tentang berbagai produk kosmetik pemutih membuat masyarakat tidak tahu dampak negatif yang timbul jika tidak berhati- hati. Merkuri dan hidrokuinon adalah beberapa zat aktif yang sering disalahgunakan oleh produsen kosmetik yang illegal. Tetapi pada kenyataanya penyalahgunaan merkuri dan hidrokuinon masih banyak dijumpai pada produk pemutih. Kegiatan ini dilakukan dengan tujuan memberikan pengetahuan dan ketrampilan kepada masyarakat terutama pasien ruang tunggu di poli rawat jalan Rumah Sakit Gunung Jati Cirebon dalam hal pengecekan nomor registrasi kosmetika. Kegiatan ini dilakukan dengan metode penyuluhan dan tanya jawab tentang materi bahaya penggunaan kosmetika pemutih yang mengandung merkuri dan hidrokuinon dilanjutkan dengan pelatihan pengecekan nomer registrasi kosmetika dengan menggunakan HP android. Dari kegiatan yang dilakukan ternyata masih banyak pasien yang belum mengetahui bahaya dari penggunaan merkuri dan hidrokuinon pada krim pemutih serta belum mengetahui bagaimana cara untuk mengecek nomor registrasi kosmetika yang beredar di pasaran. Dari kegiatan ini dapat disimpulkan bahwa pasien lebih mengetahui tentang bahaya merkuri dan hidrokuinon serta dapat mengecek langsung produk kosmetika yang biasa digunakan sehari-hari.
\end{abstract}

Kata kunci: krim pemutih, merkuri, hidrokuinon, pengecekan registrasi kosmetika

\begin{abstract}
Skin whitening products are one of the cosmetic products that contain active ingredients that can suppress or inbibit the formation of melanin or eliminate melanin that has been formed so as to give a whiter skin tone. Limitations of knowledge about various whitening cosmetic products make people do not know the negative effects that arise if not careful. Mercury and hydroquinone are some active substances that are often misused by illegal cosmetics manufacturers. But in fact the abuse of mercury and bydroquinone is still common in whitening products. This activity was carried out with the aim of providing knowledge and skills to the community, especially waiting room patients in the outpatient clinic at Gunung Jati Cirebon Hospital in terms of checking the registration number for cosmetics. This activity was carried out with counseling methods and question and answer about the material hazards of using whitening cosmetics containing mercury and Hydroquinone is followed by training in checking the registration number for cosmetics using an Android cellphone. From this activity it can be concluded that patients are more aware of the dangers of mercury and hydroquinone and can directly check cosmetic products that are commonly used everyday.
\end{abstract}

Keywords: whitening cream, mercury, bydroquinone, cosmetics registration check

\section{PENDAHULUAN}

Bahaya Merkuri dan Hidrokuinon

Memiliki kulit putih dan cerah merupakan dambaan setiap orang, terutama kaum wanita. Oleh sebab itu banyak orang yang berusaha untuk menjaga atau memperbaiki 
kesehatan kulitnya, sehingga terlihat lebih menarik. Hal tersebut didukung pula oleh perkembangan teknologi perawatan kulit serta tersebarnya klinik-klinik kecantikan di Indonesia yang menyediakan kosmetik (Tranggono, 2007).

Berdasarkan Peraturan Kepala

Badan Pengawas Obat Dan Makanan Republik Indonesia Nomor 18 Tahun 2015 Tentang Persyaratan Teknis Bahan Kosmetika, Kosmetika adalah bahan atau sediaan yang dimaksudkan untuk digunakan pada bagian luar tubuh manusia (epidermis, rambut, kuku, bibir dan organ genital bagian luar) atau gigi dan membran mukosa mulut terutama untuk membersihkan, mewangikan, mengubah penampilan dan/atau memperbaiki bau badan atau melindungi atau memelihara tubuh pada kondisi baik.

Salah satu sediaan kosmetika yang banyak digunakan oleh masyarakat terutama oleh kaum wanita adalah produk pemutih wajah. Terkadang produsen yang tidak bertanggung jawab memasukkan bahan yang berbahaya yang digunakan sebagai pemutih kulit yaitu logam merkuri $(\mathrm{Hg})$, yang dalam jangka panjang dapat menimbulkan kerusakan pada organ tubuh dan juga bersifat toksik (Wijaya, 2013).

Krim pemutih adalah salah satu jenis kosmetik yang merupakan campuran bahan kimia dan atau bahan lainnya dengan khasiat bisa memucatkan noda hitam (coklat) pada kulit. Tujuan penggunaannya dalam jangka waktu lama agar dapat menghilangkan atau mengurangi hiperpigmentasi pada kulit. Tetapi penggunaan yang terus-menerus justru akan menimbulkan pigmentasi dengan efek permanen (Citra, 2007).

Merkuri anorganik berkisar 1-10\% digunakan sebagai bahan pemutih kulit dalam sediaan krim karena berpotensi sebagai bahan pemucat warna kulit. Daya pemutih pada kulit sangat kuat, karena toksisitasnya terhadap organ-organ ginjal, saraf dan otak sangat kuat maka pemakaiannya dilarang dalam sediaan kosmetik (WHO, 2011).

$\begin{array}{ccr}\text { Menurut } & \text { Peraturan } & \text { Menteri } \\ \text { Kesehatan } & \text { RI } & \text { No. }\end{array}$
445/MENKES/PER/V/1998 tentang bahan, zat warna, substrat, zat pengawet dan tabir surya pada kosmetik. Dalam kadar yang sedikitpun merkuri dapat bersifat racun. Mulai dari perubahan warna kulit, bintik-bintik hitam, alergi, iritasi, serta pada pemakaian dosis tinggi dapat menyebabkan kerusakan permanen otak, ginjal dan gangguan perkembangan janin. Bahkan paparan jangka pendek dalam dosis tinggi dapat menyebabkan muntah-muntah, diare dan kerusakan paru-paru serta merupakan zat karsinogenik (BPOMRI, 2007).

Hidrokinon mampu mengelupas kulit bagian luar dan menghambat pembentukan melanin yang membuat kulit tampak hitam, penggunaan hidroquinon dalam kosmetik tidak boleh lebih dari $2 \%$, hidroquinon tidak boleh digunakan dalam jangka waktu yang lama,dan jika pemakaian lebih dari $2 \%$ harus dibawah kontrol dokter (FDA, 2006). Penggunaan hidroquinon yang berlebihan dapat menyebabkan ookronosis, yaitu kulit berbintil seperti pasir dan berwarna coklat kebiruan, penderita ookronosis akan merasa kulit seperti terbakar dan gatal (Astuti, 2016).

\section{Pelatihan pengecekan nomor registrasi kosmetika}

Menurut Keputusan Badan Pengawasan Obat Dan Makanan nomor hk.00.05.4.1745 tahun 2008 tentang kosmetik bab 2 persyaratan dan penggolongan, Pasal 2. Kosmetik yang diproduksi dan atau diedarkan harus memenuhi persyaratan sebagai berikut:

1. Menggunakan bahan yang memenuhi standar dan persyaratan mutu serta persyaratan lain yang ditetapkan;

2. Diproduksi dengan menggunakan cara pembuatan kosmetik yang baik;

3. Terdaftar pada dan mendapat izin edar dari Badan Pengawas Obat dan Makanan. 
Pada bab $\mathrm{V}$ tentang izin edar, bagian pertama persyaratan Pasal 10 menyatakan kosmetik sebelum diedarkan harus didaftarkan untuk mendapatkan izin edar dari Kepala Badan POM.

Tahun 2006 dan 2007 Badan Pengawas Obat dan Makanan (BPOM) Republik Indonesia telah melakukan pengujian laboratorium terhadap kosmetik yang beredar dan ditemukan 23 (dua puluh tiga) merek kosmetik yang mengandung bahan yang dilarang digunakan dalam kosmetik yaitu: Merkuri $(\mathrm{Hg})$, hidroquinon $>2 \%$ dan zat warna Rhodamin B (Sunarko, 2007).

Berdasarkan hasil pengawasan rutin Badan POM di seluruh Indonesia terhadap kosmetika yang beredar dari Oktober 2014 sampai September 2015, ditemukan 30 jenis kosmetika mengandung bahan berbahaya yang terdiri dari 13 jenis kosmetika produksi luar negeri dan 17 jenis kosmetika produksi dalam negeri. Bahan berbahaya yang teridentifikasi terkandung dalam kosmetika tersebut, yaitu bahan pewarna Merah K3 dan Merah K10 (Rhodamin B), Asam Retinoat, Merkuri dan Hidrokinon. Berdasarkan Peraturan Kepala Badan POM RI No. 2 Tahun 2014 tentang Perubahan Kedua atas Peraturan kepala Badan POM No. HK.03.1.23.08.11.07517 Tahun 2011 tentang Persyaratan Teknis Bahan Kosmetika, bahan-bahan tersebut termasuk dalam daftar bahan berbahaya yang dilarang untuk digunakan dalam pembuatan kosmetika.

Berdasarkan hal tersebut maka masyarakat perlu bijak dalam penggunaan kosmetika terutama krim pemutih, dan mengecek nomor registrasi dari sediaan kosmetika tersebut sehingga masyarakat akan lebih aman dalam penggunaan kosmetik.

Dengan berkembangnya zaman pengecekan nomor registrasi dapat dilakukan dengan menggunakan HP android, dan pada umumnya masyarakat menggunakan HP setiap harinya sehingga pengecekan tersebut dapat lebih mudah dan praktis. Pengecekan registrasi dapat dilakukan dengan menginstal di playstore.

\section{METODE}

Kegiatan penyuluhan ini dilakukan dengan menggunakan metode:

1. Ceramah

Pemateri menyampaikan uraian materi tentang bahaya penggunaan merkuri dan hidroquinon pada krim pemutih melalui media infokus. Materi yang disampaikan disertai gambaran efek samping penggunaan merkuri dan hidroquinon.

2. Tanya jawab tentang pengetahuan pasien mengenai bahaya merkuri dan hidrokuinon dilakukan sebelum materi dilakukan dan setelah materi disampaikan.

3. Pembagian brosur dan surat edaran dari BPOM yang berisi lampiran produk kosmetika yang mengandung zat berbahaya baik yang teregestrasi $\mathrm{d}$ BPOM atau pun yang tidak teregistrasi.

4. Pelatihan pengecekan registrasi kosmetika menggunakan HP android dengan cara:

a. Menginstal cek BPOM di playstore

b. Memasukkan nama produk atau nomor registrasinya

c. Pencarian produk

5. Praktek cara penginstalan dan cek registrasi kosmetika dengan menggunakan HP pasien.

\section{HASIL DAN PEMBAHASAN}

Kegiatan penyuluhan ini dilakukan dengan menggunakan metode:

1. Ceramah

Pemateri menyampaikan uraian materi tentang bahaya penggunaan merkuri dan hidroquinon pada krim pemutih melalui media infokus. Materi yang disampaikan disertai gambaran efek samping penggunaan merkuri dan hidroquinon.

2. Tanya jawab tentang pengetahuan pasien mengenai bahaya merkuri dan 
hidrokuinon dilakukan sebelum materi dilakukan dan setelah materi disampaikan.

3. Pembagian brosur dan surat edaran dari BPOM yang berisi lampiran produk kosmetika yang mengandung zat berbahaya baik yang teregestrasi $\mathrm{d}$ BPOM atau pun yang tidak teregistrasi.

4. Pelatihan pengecekan registrasi kosmetika menggunakan HP android dengan cara:

d. Menginstal cek BPOM di playstore

e. Memasukkan nama produk atau nomor registrasinya

f. Pencarian produk

5. Praktek cara penginstalan dan cek registrasi kosmetika dengan menggunakan HP pasien.Bagian ini ditulis dalam bahasa Indonesia. Spasi tunggal / satu. Jenis huruf Garamond. Ukuran huruf 12 poin. Marjin: normal.

\section{KESIMPULAN}

Dari kegiatan ini dapat disimpulkan bahwa pasien lebih mengetahui tentang bahaya merkuri dan hidrokuinon serta dapat mengecek langsung produk kosmetika yang biasa digunakan sehari-hari agar masyarakat terhindar dari penggunaan kosmetika illegal yang mengandung bahan yang berbahaya.

\section{DAFTAR PUSTAKA}

Astuti, D. W., Prasetya, H. R., \& Irsalina, D. (2016). Hydroquinone Identification in Whitening Creams Sold at Minimarkets in Minomartini, Yogyakarta. Journal of Agromedicine and Medical Sciences, 2(1), 13-20.

Badan Pengawas Obat dan Makanan Republik Indonesia. (2007). Kosmetik Mengandung Bahan Berbahaya dan Zat Warna Yang Dilarang: Keputusan Kepala Badan Pengawas Obat dan Makanan Republik Indonesia No. HK.00.01.432.6081, 1 Agustus 2007. Jakarta.

Badan Pengawas Obat dan Makanan Republik Indonesia. (2008). Keputusan Badan Pengawasan Obat dan Makanan nomor hk.00.05.4.1745 Tahun 2008 tentang Tosmetik.

Badan Pengawas Obat dan Makanan Republik Indonesia. (2015). Waspada Kosmetika Mengandung Bahan Berbahaya "Teliti Sebelum Memilih Kosmetika".

Badan Pengawas Obat dan Makanan Republik Indonesia. (2015). Peraturan Kepala Badan Pengawas Obat dan Makanan Republik Indonesia Nomor 18 Tahun 2015 tentang Persyaratan Teknis Bahan Kosmetika.

Citra, M. D. (2007). Hati-hati pakai pemutih. Diambil dari http://cybermed.cbn.net.id/cbprt/hea lth news.

Menteri Kesehatan Republik Indonesia. (1998). Peraturan Menteri Kesehatan RI No. 445/MENKES/PER/V/1998 tentang bahan, zat warna, substrat, zat pengawet dan tabir surya pada kosmetik.

Sunarko, Th dan Riana M. (2007). Analisis Unsur-unsur Toksik dalam Sampel Krim Pemutih Wajah dengan Metode Analisis Aktivasi Neutron. Jurnal penelitian Pusat Teknologi Bahan Industri Nuklir (BTBIN). Tangerang.

Tranggono, R dan Latifah F. (2007). Buku Pegangan Ilmu Pengetabuan Kosmetik. Jakarta: PT Gramedia Pustaka Utama.

Wijaya, F. (2013). Analisis Kadar Merkuri (hg) Dalam Sediaan Hand Body Lotion Whitening Pagi Merek X, Malam Merek X, Dan Bleaching Merek X Yang Tidak Terdaftar Pada BPOM. CALYPTRA, 2(2), 1-12.

World Health Organization. (2011). Mercury in skin lightening products. Public Health and Environment. Switzerland: $W H O$. 